\title{
Physical and mechanical performance of concrete made with waste rubber aggregate, glass powder and silica sand powder
}

\author{
Samiha Ramdani ${ }^{\mathrm{a}, *}$, Abdelhamid Guettala ${ }^{\mathrm{a}}$, ML Benmalek ${ }^{\mathrm{b}}$, José B. Aguiar ${ }^{\mathrm{c}}$ \\ ${ }^{a}$ Laboratory of Civil Engineering and Hydraulic (LRGC): University of Mohamed Khider,, Biskra, Algeria \\ ${ }^{\mathrm{b}}$ Laboratory of Civil Engineering and Hydraulic, University of 8 May 1945, Guelma, Algeria \\ ${ }^{\mathrm{c}}$ Laboratory of Construction Materials, University of Minho, Portugal
}

\section{A R T I C L E I N F O}

\section{Keywords:}

Rubber waste aggregates

Glass powder

Wastes combination

Mechanical strength

Deformability

Rubberized concrete

\begin{abstract}
A B S T R A C T
This study presents experimental results about the effect of incorporating waste rubber aggregates in combination with waste glass powder or silica sand powder obtained from dune natural sand, on the performances of cementitious mixtures. Rubber aggregates (RW) were used to replace crushed sand in concrete mixes with ratios of $10 \%, 20 \%, 40 \%$ and $60 \%$, while glass powder (GP) and natural sand powder (SP) were used to replace $15 \%$ of the cement weight. Nine different forms of concrete with the separate wastes and with the combination of them were designed and prepared. The mixtures were characterized in the fresh and hardened states by means of workability, fresh density, compressive and tensile strengths, propagation of ultrasonic waves and deformability tests. The water/binder ratio and superplasticizer percentage of all mixtures were maintained constant. The results showed that the strength increased with the incorporation of glass powder and rubber aggregates, especially with $10 \%$ and $20 \%$ RW contents. In addition, the developed rubberized concrete with the incorporation of glass powder presented higher fresh density and deformability, compared to the cementitious rubberized mixtures without GP. Furthermore, the simultaneous incorporation of rubber waste and glass powder enhanced the concretes workability due to the low GP and RW water absorptions.
\end{abstract}

\section{Introduction}

Over the years the world production evolution of wastes has become representing a very serious threat to the ecology. Particularly, about 270 million of discarded tires are disposed of at landfills, stockpiles or illegal dumps [1] and the number would reach 1200 million tires yearly by 2030 [2]. Locally, in Algeria alone, about $26.000 \mathrm{t}$ of worn tires are generated every year [3]. Disposal of used tires by burning is one of the cheapest and easiest methods; however, it causes serious fire hazards and environmental pollution $[4,5]$. In France, which produces over than 10 million scrap-tires per year, the supply of landfills decreased starting in July 2002, due to a new law that forbids any new landfill or burned tires in the country [6]. At that point, sustainable techniques for reuse these wastes need to be created. Among these techniques, is the use of discarded tire as a fuel in cement kilns, road construction, civil engineering applications specially geotechnical works and aggregate in cement-based products. Despite the risk of the discarded tire problem, in Algeria it is still limited to geotechnical works; as the project of stability of an embankment road using the tyresol technique, situated at Bousmail city (northern of Algeria) [7].
From another point of view, the use of industrial waste as a substitute material can very well help preserve the limited natural resources as reported by Bostanci et al. [8].

Recently, researchers worldwide up the challenge to assess the usability of this industrial waste in cementitious materials, however, their performance has to be defined. The most recent studies related to the use of rubber aggregates and chips obtained from the used tires milling as a partial replacement of fine and coarse aggregates should be highlighted [9-24]. Blessen et al. [9] studied the properties of high strength rubberized concrete that contains scrap tire rubber. Crumb rubber was used to replace natural fine aggregate from $0 \%$ to $20 \%$ in multiples of $2.5 \%$. It was observed a significant improvement on the abrasion resistance and water absorption properties, while mechanical and durability of high strength rubberized concrete were observed to be less than that of the control mix. Similarly, Ganjian et al. [10] tested the effect of replacing coarse aggregates by chipped tire and cement by powder tire crumb. Based on the results, they obtained a reduction in compressive strength about $10-23 \%$ and $20-40 \%$ for replacing natural aggregates and cement with chipped rubber, powder rubber respectively. In addition, Aslani et al. [11] practiced the replacement of

\footnotetext{
* Corresponding author.

E-mail address: Samiha_ramdani@hotmail.com (S. Ramdani).
} 
natural aggregates with three sizes of rubber aggregates $2 \mathrm{~mm}, 5 \mathrm{~mm}$ and $10 \mathrm{~mm}$ at volume ratios of $10 \%, 20 \%, 30 \%$, and $40 \%$ to promote the physical and mechanical properties of Self-compacting concrete. They stated that rubber aggregates that were replaced at $10 \%$, all achieved a compressive strength greater than $30 \mathrm{MPa}$ and the increasing of crumb rubber aggregates size showed an increase in the maximum peak strains. Furthermore, investigations on the use of recycled tire rubber in the materials utilizing in the base and subbase layers of pavement have been made by Jie Li et al. and Saberian et al. $[12,13]$. Jie Li et al. [12] studies the effects of crumb rubber and its size fine (ranging from 400 to $600 \mu \mathrm{m}$ ), coarse (ranging from 10 to $15 \mathrm{~mm}$ ) on the mechanical properties of recycled construction and demolition (C\&D) aggregates as the base/subbase layers of pavement. Based on the experimental test results, it was found that the inclusion of both coarse and fine rubbers led to an increase in the deformability index and failure strain compared to the control one. From the Clegg impact hammer test results, it was concluded that the strength of the aggregates increased with the content of fine rubber but decreased with the content of coarse rubber values. In the same context, the experimental study of Mohammad Saberian et al. [13] about the effects of crumb rubber and rubber size on permanent deformation behavior of recycled concrete (RCA) and crushed rock (CR) aggregates showed larger permanent strains and slower decrease in permanent strain rate for CR samples by increasing the crumb rubber content.

As a consequence, according to the following studies [9,10,14-18] the replacement of natural aggregates with tire rubber aggregates considerably decreases the concrete and mortar strengths; while rubberized mixtures [11,19-22] demonstrated a greater deformability and ductility compared with common mixes.

After that, efforts have been carried about improving the strength and durability of rubber cementitious materials. Many works have mentioned the use of pre-treated RW (rubber wastes) by immersion in $\mathrm{NaOH}$ solution [23], by the use of styrene butadiene rubber (SBR) [24] and silane coupling agent as cementitious layer [18] to increase the adhesion between the cement paste and the rubber particles. Other studies have been carried out based on the incorporation of additive materials into rubber mixtures such as silica fume (SF) as pointed by Obinna et al. [25] and Topçu et al. [26]. They replaced cement with silica fume into rubber mixtures with $15 \%, 10 \%$ ratios respectively. They found a marked improvement in strength and resistance to chloride penetration, also a reduction in water, and gas permeability coefficients was observed. Lime stone [18], fly ash and metakaolin were also used to enhance the properties and the durability of concrete with tire rubber waste [27]. There have also been investigations into using recycled concrete aggregates (RA) in combination with recycled crumb rubber (CR) to optimize the high-performance self-compacting concrete properties [28]. The study found that combined RA with CR in selfcompacting concrete produced the lowest compressive strengths. In addition, Aslani et al. [29] studied the properties of self-compacting rubberized concrete incorporating polypropylene (PP) and steel fibers. They using crumb rubber sizes of $2-5 \mathrm{~mm}$, as replacement of $20 \%$ of fine aggregates and $0.1 \%, 0.15 \%, 0.2 \%, 0.25 \%$ of PP fibers, as well as, $0.25 \%, 0.5 \%, 0.75 \%, 1 \%$ for the steel fibers. Based on the results, it was observed a minor increase of the compressive and tensile strengths with the increase of steel fibers content.

However, the utilization of glass powder waste (GP) in replacement of cement into rubber cementitious materials had not been studied in spite of its pozzolanic reaction with the lime. The glass powder added as weight replacement of cement to the basic rubber mixtures can compensate the loss of compactness associated to the incorporation of RW (rubber waste).

The usability of fine glass powder as a value-added product as it could replace a proportion of an expensive concrete constituent, such as Portland cement was possible [30,31]. The Recyc Quebec [32] analysis showed that valorizing glass bottles as GP in concrete can allow for its transportation within a radius of $8950 \mathrm{~km}$ without environmental impacts compared to landfilling. So, using GP as a cement replacement has very little environmental impact [33]. The results of this research were a challenge for use of glass powder waste in the production of concrete. Abdo Ali et al. [34] and others [35,36] investigated the effect of using glass powder as cement replacement, they concluded that using up to a $10 \%$ rate enhanced the mortar and concrete compressive strengths. Cementitious materials expansion due to the alkali-silica-reaction behavior can appear when the reactive silica from glass reacts with the alkali from cement. Bignozzi [37] concluded that the chemical composition and dimension of different glass sources in the supplementary cementing materials (SCM) behavior, is a key point for its potential expansion behavior (ASR). Particularly, it was reported that ground soda-lime glass with dimension $<300 \mu \mathrm{m}$ can safely be introduced in concrete [31,32]. Add to this, Schwarz et al. [38] compared the effect of glass powder modified concrete to that modified with fly ash. It has been proven by this study that the increase in fineness of glass powder improved strength and durability performances of concrete. Similar results were reported by other researchers [39-42]. So, it should be noted that the pozzolanic reactivity of glass powder is directly related to its particle size. Also, Soliman [33] worked in the development of ultra-high-performance concrete using glass powder showing encouraged physical and mechanical results.

To the best of our knowledge, previous works have only focused on the combined use of rubber and many additives on production of concrete as mentioned in the precedent section. However, there has been limitation knowledge related to the combined use of rubber aggregates and glass powder wastes on concrete. To fill this knowledge gap, it is proposed, in this study, to demonstrate the performance of the eco-materials with those wastes. The main objective of the study is the use of rubber of discarded tire and glass bottle in the production of new eco-concrete, which helps to reduce those wastes. This study is to provide the results of experimental investigations on physical and mechanical properties of this concrete where crush sand was replaced by RW aggregates and glass powder replaced cement or both. The amounts of replacement used were $10-20 \%-40 \%$ and $60 \%$ by volume for RW and $15 \%$ by weight for GP. The compressive and tensile strengths, fresh unit weight, workability, ultrasonic waves and deformability of the studied concretes were experimentally made. In addition, an investigation comparing the effects of artificial powder glass bottle waste material with a powder of natural sand on the performance of concrete was made in this study.

\section{Materials and methods}

\subsection{Materials}

\subsubsection{Cement}

A local ordinary Portland cement (CEM II 42.5) produced by the cement plant of Hadjar Soud (Department of Skikda, northern of Algeria), complying with Algerian Standard NA 442 was used as a binder for all the mixtures. Its absolute density and specific area were $3.1 \mathrm{~g} / \mathrm{cm}^{3}$ and $3200 \mathrm{~cm}^{2} / \mathrm{g}$ respectively. Its chemical composition is given in Table 1. The laser granulometry curve is shown in Fig. 1(a) and the photomicrograph at a magnification of 5.000, in Fig. 2.

\subsubsection{Waste glass bottle powder (GP)}

This powder is the outcome of the glass bottles recovery in landfills. It was obtained by selecting only the bottles of the same color (green). These were cleaned, crushed and finely grounded by an electric mill without any treatment. According to the usual classification of the French standard NF XP 18-540; the glass powder was classified as filler material because $74 \%$ of the particles passed though the sieve of $36 \mu \mathrm{m}$. Chemical analysis determined using X-ray fluorescence technique (XRF) is presented in Table 2. The basic component $(73.6 \%)$ was the silica dioxide $\left(\mathrm{SiO}_{2}\right)$ and the proportion sum of $\mathrm{SiO}_{2}, \mathrm{Al}_{2} \mathrm{O}_{3}$ and $\mathrm{FeO}_{3}$ was $75.8 \%\left({ }^{>} 70 \%\right)$ allowing to the used glass powder to be classified as a 
Table 1

Chemical compositions of the used Portland cement.

\begin{tabular}{lclr}
\hline Chemical composition & $(\%)$ & Clinker composition & (\%) \\
\hline $\mathrm{CaO}$ & $56-63$ & $\mathrm{C}_{3} \mathrm{~S}$ & $50-65$ \\
$\mathrm{Al}_{2} \mathrm{O}_{3}$ & $4-6$ & $\mathrm{C}_{2} \mathrm{~S}$ & $10-25$ \\
$\mathrm{SiO}_{2}$ & $19-27$ & $\mathrm{C}_{3} \mathrm{~A}$ & $9-12$ \\
$\mathrm{Fe}_{2} \mathrm{O}_{3}$ & $2.5-3.5$ & $\mathrm{C}_{4} \mathrm{AF}$ & $7-11$ \\
$\mathrm{MgO}$ & $1-2$ & & \\
$\mathrm{Na}_{2} \mathrm{O}$ & $0.1-0.6$ & & \\
$\mathrm{~K}_{2} \mathrm{O}$ & $0.3-0.6$ & & \\
$\mathrm{Cl}^{-}$ & $0-0.2$ & & \\
$\mathrm{SO}_{3}$ & $2-3$ & & \\
Free $\mathrm{CaO}$ & $0.5-2.5$ & & \\
\hline
\end{tabular}
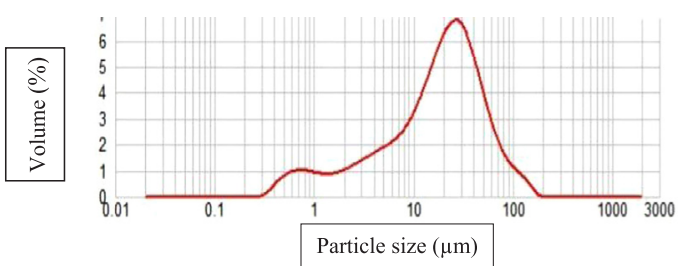

(a)

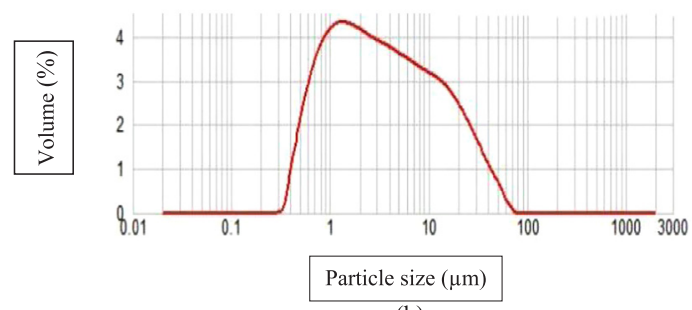

(b)

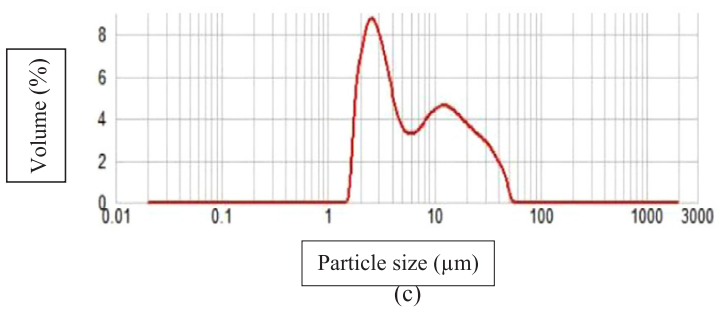

Fig. 1. Laser granulometry curves of: (a) cement, (b) natural sand and (c) glass powders.

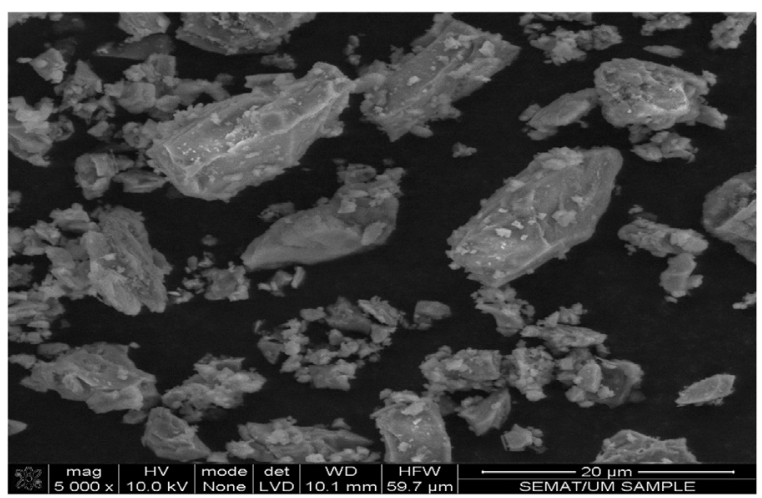

Fig. 2. Cement photomicrograph (X 5000).

good pozzolan according to the ASTM C618-02 norm. The morphology of glass powder using scanning electron microscopy (SEM) at a magnification of 5.000 is shown in Fig. 3.
Table 2

Chemical compositions of glass and sand powders.

\begin{tabular}{llr}
\hline Chemical composition & GP (\%) & SP (\%) \\
\hline $\mathrm{SiO}_{2}$ & 73.60000 & 93.60000 \\
$\mathrm{TiO}_{2}$ & 0.02560 & 0.09700 \\
$\mathrm{Fe}_{2} \mathrm{O}_{3}$ & 0.79700 & 1.48000 \\
$\mathrm{Al}_{2} \mathrm{O}_{3}$ & 1.44000 & 1.70000 \\
$\mathrm{CaO}$ & 8.04000 & 2.25000 \\
$\mathrm{MgO}$ & 2.78000 & 0.15300 \\
$\mathrm{SO}_{3}$ & 0.23600 & 0.03550 \\
$\mathrm{Cr}_{2} \mathrm{O}_{3}$ & 0.04700 & 0.23600 \\
$\mathrm{ZnO}_{2}$ & 0.00773 & 0.01510 \\
$\mathrm{BaO}$ & 0.01380 & 0.00776 \\
$\mathrm{~K}_{2} \mathrm{O}$ & 0.34400 & 0.29600 \\
$\mathrm{Na}_{2} \mathrm{O}$ & 12.60000 & 0.02900 \\
$\mathrm{Sn}$ & $/ /$ & 0.00478
\end{tabular}

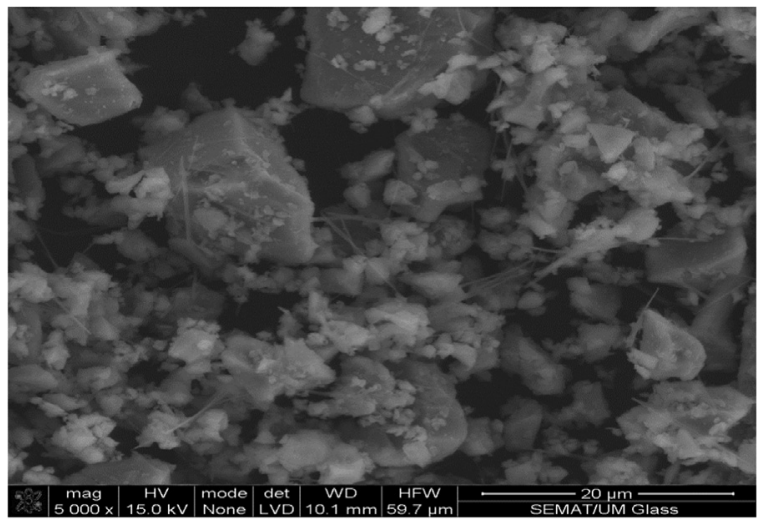

Fig. 3. Glass powder photomicrograph (X 5000).

\subsubsection{Natural sand powder (SP)}

The sand powder was obtained by mechanical grinding (electric mill) of the same natural sand utilized in the mixtures. Its absolute density was $2.54 \mathrm{~g} / \mathrm{cm}^{3}$. Its chemical composition and distribution size are reported in Table 2 and Fig. 1(b), respectively. The principal component (i.e. $\mathrm{SiO}_{2}$ ) rate is $93.6 \%$, much important compared to the glass nature one. Its photomicrograph is shown in Fig. 4 and its aspect in the picture of Fig. 5(c).

\subsubsection{Fine aggregates}

These are natural sand (NS) and artificial crushed sand (CS). The NS was collected from Boussada (Department of Msila, northern Algeria). It has a siliceous nature with $93.6 \%$ of $\mathrm{SiO}_{2}$. Its fineness modulus and absolute density were 1.33 and 2.54 respectively while its sand equivalent assessing its cleanliness was equal to 70. Fig. 6 exhibits its

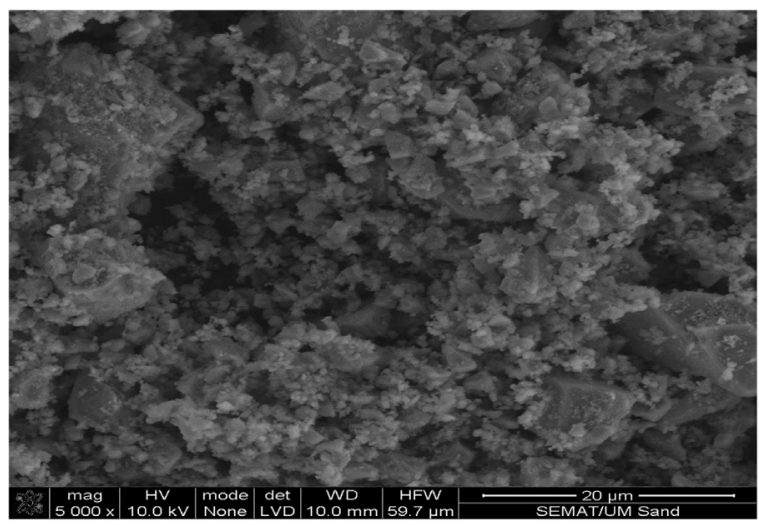

Fig. 4. Sand powder photomicrograph (X 5000). 


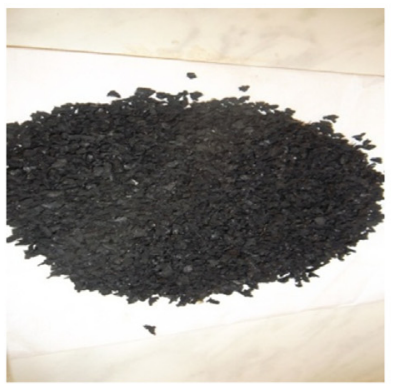

(a)

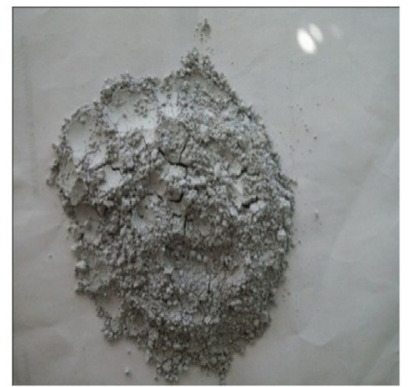

(b)

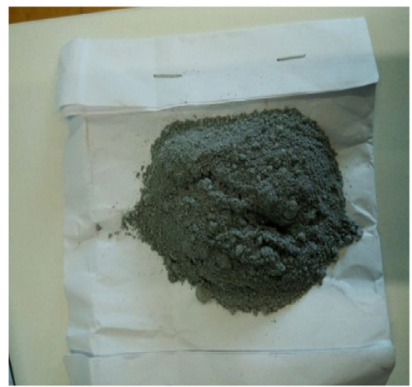

(c)

Fig. 5. (a) Recycled waste of tire, (b) Glass bottle powder and (c) Sand powder.

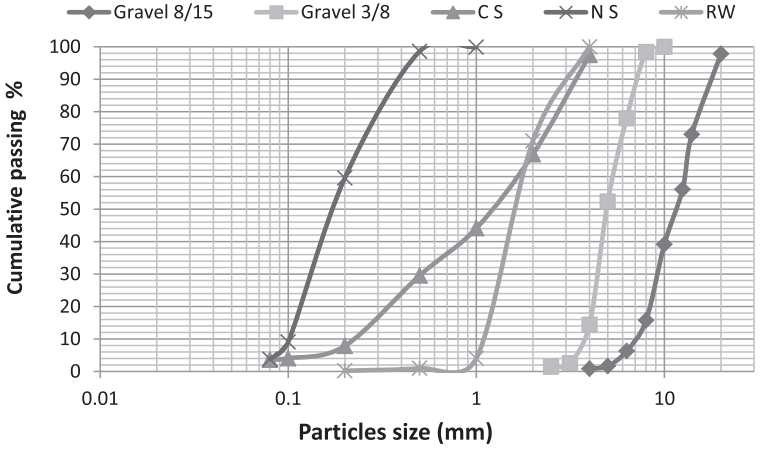

Fig. 6. Grain size analysis of the used raw materials.

particle size distribution as well as that of CS, RW and coarse aggregates.

The (CS) was collected from a career located at Ain Touta in Souk Ahras department (eastern Algeria). It is a calcareous sand with an absolute density of 2.51 and a fineness modulus of 3.51. Its maximum particle size, as determined by sieving method, was $4.5 \mathrm{~mm}$ (Fig. 6).

\subsubsection{Coarse aggregates}

Two types of calcareous gravels collected from the same career of Ain Touta, having $3 / 8 \mathrm{~mm}$ and $8 / 15 \mathrm{~mm}$ in dimensions, were used to manufacture the reference concrete. Their distribution curves, as presented in Fig. 6, are continuous and their absolute density and water absorption were $2.5 \%$ and $1.75 \%$ respectively.

\subsubsection{Rubber waste aggregates (RW)}

Rubber waste aggregates (without steel fibers) used in this study were obtained by mechanical grinding of worn tires from a local factory
(Algeria). Their dimensions were ranged between 0.2 and $4 \mathrm{~mm}$ (Fig. 6). Its absolute density, as calculated according to ISO 2781-2008 code, was found to be $0.98 \mathrm{~g} / \mathrm{cm}^{3}$ and its aspect is shown in Fig. 5(a).

\subsubsection{Superplasticizer}

Superplasticizer used in the concrete mixes named Master Glenium 24 , is based on modified ether polycarboxylic according to the standard EN 934-2:2012. It ensures high water reduction, high performance and very long workability. It was used at $0.5 \%$ of the cement weight to control the workability of the studied rubberized concrete.

\subsection{Mixture proportions}

As part of the valorization of local materials, all the raw materials used in this study, detailed in the previous section, were local.

An extensive concrete testing program was conducted to achieve optimum reference concrete (C-ref) without any additive, having optimal mechanical strengths, and plastic workability. The cement dosage was fixed to $400 \mathrm{~kg} / \mathrm{m} 3$. Quantities of granular components were obtained by Deux-Gorisse method [43] while water and superplasticizer were determined experimentally on the basis of slump test (NF EN $12350-2$ ) to achieve a slump value about $60 \mathrm{~mm}$ corresponding to a plastic concrete.

Based on results of these preliminary tests, the optimal 28 days compressive strength was obtained after crushing tests on several cylinders $160 \mathrm{~mm}$ x $320 \mathrm{~mm}$ prepared and cured at ambient temperature of $21 \pm 2{ }^{\circ} \mathrm{C}$ according to the American standard ASTM C39. The corresponding mixture proportions are presented in Table 3 as C-ref mixture and its characteristics are summarized here after: 28 days compressive strength $=40.08 \mathrm{MPa}, 28$ days tensile strength, as determined in accordance with ASTM C496 $=4.66 \mathrm{MPa}$, average slump $=60 \mathrm{~mm}$, fresh density $=2.47$ and $\mathrm{W} / \mathrm{C}=0.43$.

Table 3

Mix proportions per cubic meter of concrete.

\begin{tabular}{|c|c|c|c|c|c|c|c|c|c|c|}
\hline Mixes & $\mathrm{PC} \mathrm{kg}$ & NS kg & CS kg & Gravel 3/8 kg & Gravel 8/15 kg & RW kg & GP kg & SP kg & W L & SP-Plast \\
\hline C-ref & 400 & 87.47 & 484.2 & 103.32 & 1050.6 & - & - & - & 172 & 2 \\
\hline 10RW & 400 & 87.47 & 436 & 103.32 & 1050.6 & 19 & - & - & 172 & 2 \\
\hline 20RW & 400 & 87.47 & 387 & 103.32 & 1050.6 & 38 & - & - & 172 & 2 \\
\hline 40RW & 400 & 87.47 & 290 & 103.32 & 1050.6 & 76 & - & - & 172 & 2 \\
\hline $60 \mathrm{RW}$ & 400 & 87.47 & 194 & 103.32 & 1050.6 & 113 & - & - & 172 & 2 \\
\hline 0RW15GP & 340 & 87.47 & 484.2 & 103.32 & 1050.6 & - & 60 & - & 172 & 2 \\
\hline 0RW15SP & 340 & 87.47 & 484.2 & 103.32 & 1050.6 & - & - & 60 & 172 & 2 \\
\hline 10RW15GP & 340 & 84.93 & 436 & 101.72 & 1050.6 & 19 & 60 & - & 172 & 2 \\
\hline 20RW15GP & 340 & 84.93 & 387 & 102.05 & 1050.6 & 38 & 60 & - & 172 & 2 \\
\hline 40RW15GP & 340 & 84.93 & 290 & 102.72 & 1050.6 & 76 & 60 & - & 172 & 2 \\
\hline 60RW15GP & 340 & 85.57 & 194 & 103.32 & 1050.6 & 113 & 60 & - & 172 & 2 \\
\hline 10RW15SP & 340 & 87.47 & 436 & 103.32 & 1050.6 & 19 & - & 60 & 172 & 2 \\
\hline 20RW15SP & 340 & 87.47 & 387 & 103.32 & 1050.6 & 38 & - & 60 & 172 & 2 \\
\hline 40RW15SP & 340 & 87.47 & 290 & 103.32 & 1050.6 & 76 & - & 60 & 172 & 2 \\
\hline 60RW15SP & 340 & 87.47 & 194 & 103.32 & 1050.6 & 113 & - & 60 & 172 & 2 \\
\hline
\end{tabular}

SP-Plast $=$ Superplasticizer. 


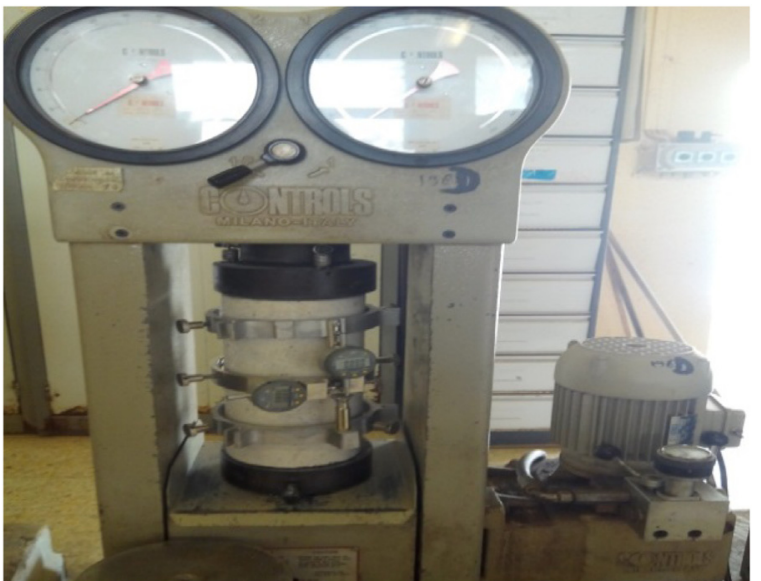

Fig. 7. Experimental set-up of stress-strain measured during compressive test.

After that, 15 different mixtures were prepared with the same water/binder ratio at 0.43 level and superplastisizer percentage at $0.5 \%$, one control concrete (C-ref) for comparison and 14 others with different amounts of rubber waste (RW), glass powder (GP) and sand powder (SP). The fifteen mixtures proportions are listed in Table 3.

The dry solid components were mixed for $3 \mathrm{~min}$. Once the mixture was homogeneous, a solution containing $80 \%$ of water with the totality of the superplasticizer was added and mixed for $2 \mathrm{~min}$. After that, the $20 \%$ of water was added and the mixtures were mixed for more 2 min. All mixtures were prepared in a pan mixer in a laboratory and then cast in steel moulds. After removing from the steel moulds $24 \mathrm{~h}$ later, the mixtures were cured in clean water at $21-23^{\circ} \mathrm{C}$ until the age of the tests. The tendency of crumb rubber to the top of the sample during vibration is possible, due to their low specific gravity. For that reason, vibration with poker was utilized to make the rubberized mixtures more homogeneous.

\subsection{Experimental test procedures}

\subsubsection{Workability}

The slump test was used to investigate the influence of RW, GP and SP on the workability of studied concrete. Each reported value was the average of measurements of two tests for all mixtures.

\subsubsection{Fresh density}

The density of studied concrete specimens was calculated by dividing the mass by the volume of the concrete cube specimens of $100 \mathrm{~mm}$ is a side in the fresh state after table vibration directly. Each reported value was the average of measurements of three tests for all mixtures.

\subsubsection{Compressive strength test}

The compressive strength test was performed at 7 and 28 days in accordance with the standard ASTM C39. The moulds were cylinders $160 \mathrm{~mm} \times 320 \mathrm{~mm}$. The demoulding occurred after $24 \mathrm{~h}$. The specimens were cured in water at a temperature of $21 \pm 2{ }^{\circ} \mathrm{C}$. The compressive strength was obtained from an average of three tests. The compressive strength measurements were carried out using an automatic testing machine with a capacity of $3000 \mathrm{kN}$.

\subsubsection{Tensile splits strength test}

The tensile strength test was determined following the standard ASTM C496. Two cylinders with the same dimensions mentioned in 2.3.2 were prepared, for each mixture and cured in water at temperature $21 \pm 2{ }^{\circ} \mathrm{C}$ until the age of 28 days. In the splitting test, the concrete cylinder is placed horizontally between the press platens and the load is increased to the point of rupture by indirect traction, which occurs as a split along the vertical diameter of the press.

\subsubsection{Ultrasonic pulse velocity test}

The incorporation of the crumb rubber into the concrete affects the air voids and compactness. Therefore, the ultrasonic pulse velocity test is necessary to assess the influence of crumb rubber on the compactness of the specimens. The ultrasonic pulse velocity test (non-destructive) was used following NF EN 12,504-4 standard. It's consists on holding the two poles for computing the pulse velocity, each one in the sides of the cylinder $(160 \mathrm{~mm} \times 320 \mathrm{~mm})$ and reading the transmission time. Pulse velocity was calculated by employing the following equation:

$\mathrm{V}=\frac{\mathrm{L}}{\mathrm{T}}$

where, "V" is pulse velocity (m/sec), "L" is the distance between two transducers (mm) equal to $320 \mathrm{~mm}$, and " $\mathrm{T}$ " is the transmission time (sec). The ultrasonic pulse velocity measurements were performed using two specimens of each mixture.

\subsubsection{Deformability and static modulus of compressive test}

The deformability test was performed to determine the stress-strain behavior and the static modulus of elasticity of the mixtures, with the agreement of ASTM C469 standard using a compressometer/extensometer model 55-C0221/D under the axial compression action (see Fig. 7). Three cylindrical specimens of $160 \mathrm{~mm}$ x $320 \mathrm{~mm}$ of each mixture were produced and cured for 28 days. Controls hydraulic press with a capacity of $3000 \mathrm{kN}$ was used to apply the load. The stress-strain curves were determined by measuring the relative displacement of datum points on the cylinder surface during extensometer experiment three times for all the mixtures.

\section{Results and discussion}

\subsection{Workability}

All slump values of tested mixtures are presented in Fig. 8. It was observed that there was a global decrease in the slump of the following mixes (10RW, 20RW, 40RW and 60RW) and with respect to RW replacement rates; in particular, the slump values reduced from $6 \mathrm{~cm}(\mathrm{C}$ ref) to $5.5 \mathrm{~cm}$ (10RW), $5 \mathrm{~cm}$ (20RW), $4 \mathrm{~cm}$ (40RW) and $4.5 \mathrm{~cm}$ (60RW), respectively. The results thus obtained are compatible with those conducted by $[11,16,18,26]$. The most likely explanation of this decrease in workability is the hydrophobic nature, particles shapes and cracks of rubber aggregates (Fig. 5(a)), part of the water trapped between this cracks serves for segregation and less homogeneous of the mixtures. Similar to Aslani et al. [11] who's attributed the reason for this slump decrease to the rubber aggregates shape which affects the concrete consistency.

Regarding the effect of glass and sand powders (GP and SP) replacement on the reference concrete workability, it can be observed that slumps increases from $6 \mathrm{~cm}$ (C-ref) to $7.5 \mathrm{~cm}$ and $7 \mathrm{~cm}$ for (0RW15GP) and (0RW15SP) mixes, respectively. So far, there is no general agreement on the glass concrete slump; it was often discussed, yet rarely well understood. The slump increase of glass mixes (without

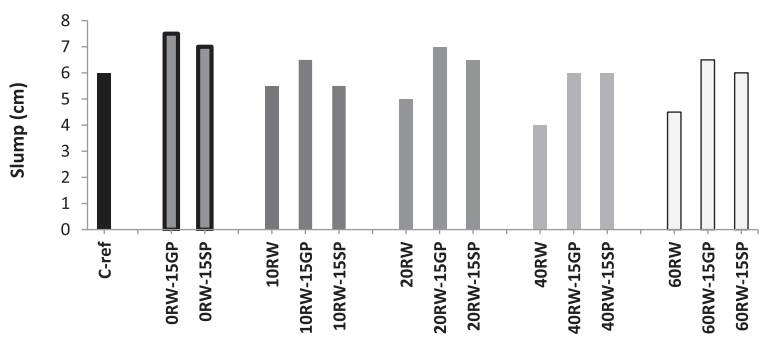

Fig. 8. Workability of the prepared mixtures. 
rubber) may be due to the low water absorption of the glass powder which raises the percentage of water in the matrix, then, in turn, increases the workability. Add to this, mixtures containing cement and glass powder were found to require less superplasticizer than the mixture designed with cement alone $[44,45]$.

In the same context, the effect of SP replacement on slump values of reference concrete is close to those with GP, only about $1 \mathrm{~cm}$ of difference due to the lower GP water absorption compared with SP. In addition, may be due to the minor difference in quantities of individual compounds between glass and sand powders (Table 2). Also, SP particles are closer to spherical shape than GP particles as shown in (Figs. 3 and 4). Moreover, this can be attributed to the difference between SP and GP grains distribution (Fig. 1), while the sand powder has a unimodal distribution, glass powder is bimodal. Guettala et al. [46] studied the effect of partial replacement of cement with sand powder; they reported that the granular effect relates to all the modification, was induced by the presence of the mineral additions in the granular structure of the cementitious materials in a fresh state.

Where data of separate effect of the rubber waste and the powders are compared to the effect of combined of them (RW-GP) and (RW-SP) on concrete. The slump values were $5.5 \mathrm{~cm}, 6.5 \mathrm{~cm}$ and $5.5 \mathrm{~cm}$ for the mixes (10RW), (10RW15GP) and (10RW15SP) respectively; and $5 \mathrm{~cm}$, $6.5 \mathrm{~cm}$ and $7 \mathrm{~cm}$ for the mixes (20RW), (20RW15GP), (20RW15SP) respectively. It can be seen that the incorporation of the combined (RWGP) granulates allowed an increase of workability in the studied rubberized concrete. This may be due to the capacity of the fine particles of glass powder to filling the voids between the grains and releasing the water from these voids, creating a new porosity network. Furthermore, it can be explained by the synergetic effect of the difference in particle's shape and size of both, cement and glass powder (Figs. 2 and 3) which created a friction between them that leads to increasing workability. Concluded glass and sand powders can improve rubberized concrete flow.

\subsection{Fresh density}

All values of fresh density of tested concrete mixtures are illustrated in Fig. 9. They ranged from $2404 \mathrm{~kg} / \mathrm{m}^{3}$ to $2147 \mathrm{~kg} / \mathrm{m}^{3}$ depending on glass, sand powders and rubber contents. It can be seen, for the mixes with rubber aggregates that the density decreases from $2404 \mathrm{~kg} / \mathrm{m}^{3}$ (reference concrete) to $2147 \mathrm{~kg} / \mathrm{m}^{3}$ for $60 \mathrm{RW}$. At $60 \%$ rubber content, its decrease to as low as about $10.7 \%$ compared with the reference one, attributable to the low absolute density of RW aggregates $\left(0.98 \mathrm{~g} / \mathrm{cm}^{3}\right)$, irrespective of glass and sand powders content. Moreover, this reduction can be explained by the segregation caused by the rubber aggregates during the mixing of concrete which leads to the development of air content. Comparative results were noted by other authors $[2,17,22]$. According to E Guneyisi et al. [16], the increasing rubber content reduced the fresh unit weight of the concrete. They concluded that at $50 \%$ rubber content, the unit weight diminished to as low as about $75 \%$ of the normal concrete.

The effect of GP and SP in the density of concretes was observed on

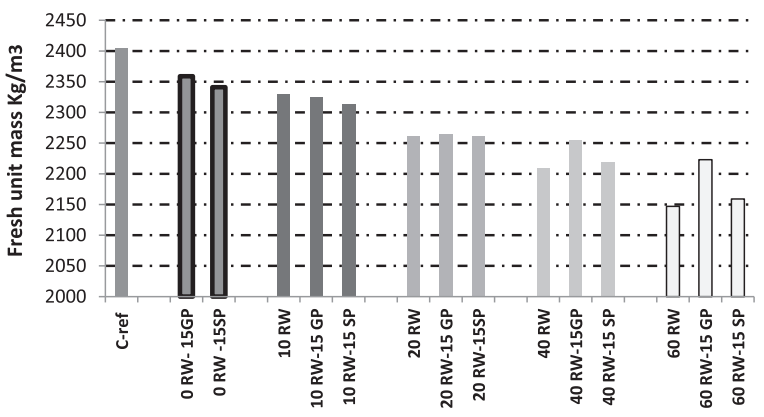

Fig. 9. Fresh density of concrete mixtures. the second part of the Fig. 9. One can see a slight reduction in the mixes 0RW15GP and 0RW15SP about $1.88 \%$ and $2.62 \%$ compared to the reference concrete. This is due to the low GP and SP densities $(2.18 \mathrm{~g} /$ $\mathrm{cm}^{3}$ and $2.54 \mathrm{~g} / \mathrm{cm}^{3}$ respectively) in comparison to the cement which were replaced $\left(3.1 \mathrm{~g} / \mathrm{cm}^{3}\right)$.

The fresh density values obtained from the reference rubberized concrete (20RW), (40RW), (60RW) were $2262 \mathrm{~kg} / \mathrm{m}^{3}, 2210 \mathrm{~kg} / \mathrm{m}^{3}$ and $2147 \mathrm{~kg} / \mathrm{m}^{3}$ respectively; and the corresponding values of fresh density modified with GP were $2265 \mathrm{~kg} / \mathrm{m}^{3}, 2254 \mathrm{~kg} / \mathrm{m}^{3}$ and $2223 \mathrm{~kg} / \mathrm{m}^{3}$. After comparing these results it can be noticed that the combined replacement of (RW-GP) in concrete creates a compromise between the separate effects of them. This synergetic effect can be attributed to the ability of GP specific area (finer amorphous silica) to fill the voids caused by crumb rubber addition, where it is greater than cement it replaced. Ali et al. [34] studies the replacement of cement by GP on mortar, they concluded that the use of glass powder refines the pores of cement paste and this reflects the mortar and concrete properties. A similar behavior with a little reduction was observed for the mixtures with the same crumb rubber replacement ratios when SP was added to the concrete but, with lower effectiveness.

\subsection{Compressive and tensile strengths}

The 7 and 28 days compressive strengths $\left(R_{c 7}\right.$ and $\left.R_{c 28}\right)$, as well as the 28 days tensile strengths $\left(R_{t 28}\right)$ obtained on $16 \mathrm{~cm} \mathrm{x} 32 \mathrm{~cm}$ cylinder specimens for all the mixes are reported in the Fig. 10. It is well known that addition of rubber wastes in cementitious composites leads to compressive and tensile strength loss $[3,10,11,14-16,28]$, contrary, they show a greater deformability and ductility compared with common mixes $[11,19,22]$. Particularly, it should be mentioned that the loss in $\mathrm{R}_{\mathrm{c} 28}$ of the mixes $10 \mathrm{RW}$ and $20 \mathrm{RW}$, is about $16.27 \%$ and $25.75 \%$ respectively, with respect to reference concrete (C-ref). In $\mathrm{R}_{\mathrm{t} 28}$, it is about $1.51 \%$ and $3 \%$ respectively. In addition, the mixes with higher rubber percentages 40RW and 60RW show a significant compressive strength loss; estimated at $48.26 \%$ and $64.95 \%$, respectively. It is to be noted that the $\mathrm{R}_{\mathrm{c} 28}$ loss is greater than that of $\mathrm{Rt}_{28}$ (Fig. 11 and Fig. 12). These results agree with the earlier field investigation $[6,14-17]$. Authors explained this strength loss by the week bond between the crumb rubber as organic material and the binder of cement as inorganic material. Also, the reduction in splitting tensile strength is ascribed to the same factors which affected the compressive strength of specimens $[10,11,25,28]$. The pictures of Fig. 13 and Fig. 14 show the failure pattern of specimens after 28 days compressive and split tensile tests, respectively. The control concrete exhibited brittle and sudden failure while the rubberized concrete shows more ductile failure under compression loading. Clear break was observed for the control specimens and horizontal cracks were observed with the rubberized

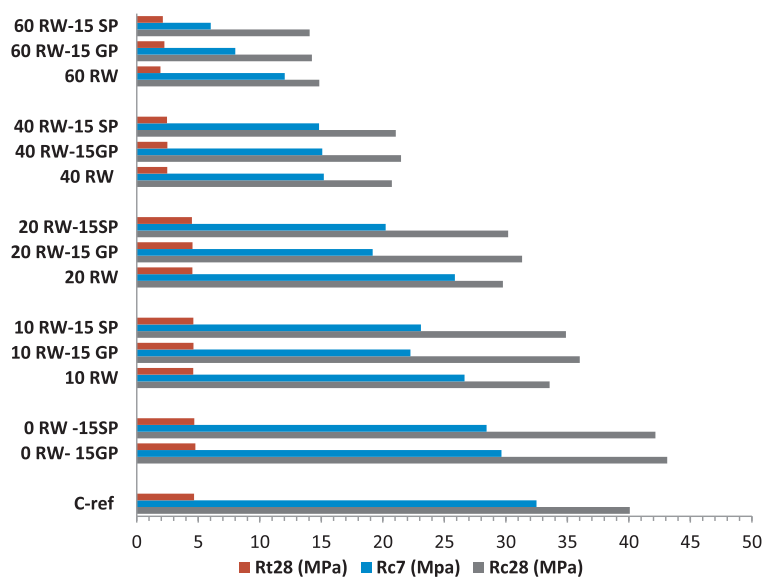

Fig. 10. Compressive $\left(R_{c 28}\right),\left(R_{7}\right)$ and tensile $\left(R_{t 28}\right)$ strengths for all mixtures. 


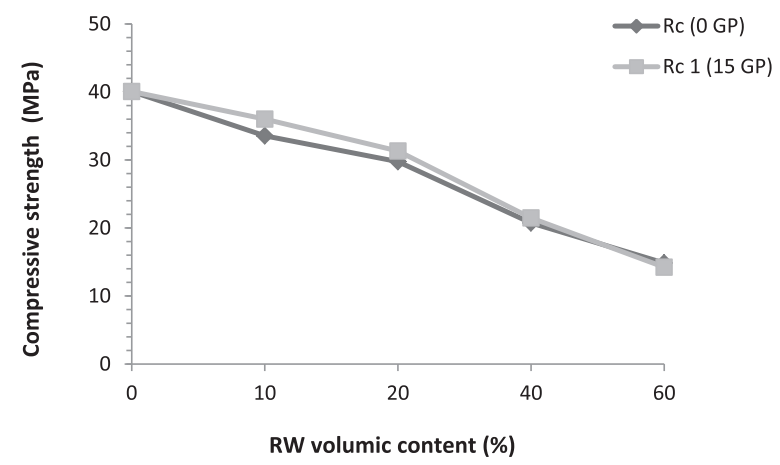

Fig. 11. Effect of GP incorporation with RW on the 28 days compressive strength.

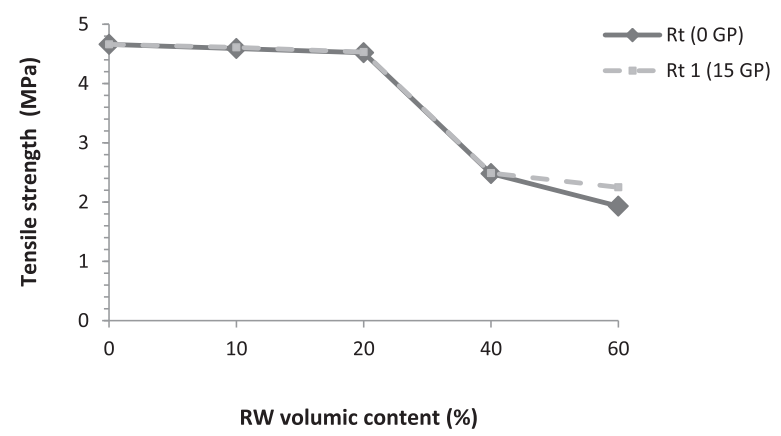

Fig. 12. Effect of GP incorporation with RW on the 28 days tensile strength.

specimens.

Compared to the rubberized concrete mixtures, the combined GP with RW on concrete affects the accompanied decrease of compressive strength at 7 days $\left(\mathrm{R}_{\mathrm{c}}\right)$ with respect to the RW contents. This indicates that the hydration reactions are slow with the replacement of the part of cement by glass powder at the early age (7 days). It can be due to the slow rate of reaction between $\mathrm{SiO}_{2}$ from glass powder and $\mathrm{Ca}(\mathrm{OH})_{2}$ from cement which led to a reduction of hydration products (C-S-H), accompanied by a decrease in the amount of $\mathrm{C}_{3} \mathrm{~S}$ and $\mathrm{C}_{2} \mathrm{~S}$ (the three are responsible for the concrete strength) in the mixtures. Our results share a number of similarities with Soliman et al. [33], Ali abdo et al. [34] and Valeria et al. [47] findings of the negative effect of glass powder on cementitious materials compressive strength at an early age (7days). On the other hand, $\mathrm{R}_{\mathrm{c} 7}$ of the composed (RW-SP) mixes is also observed to be lower compared with the rubberized mixtures, when is higher compared to the ones modified with GP. This may be due to the better
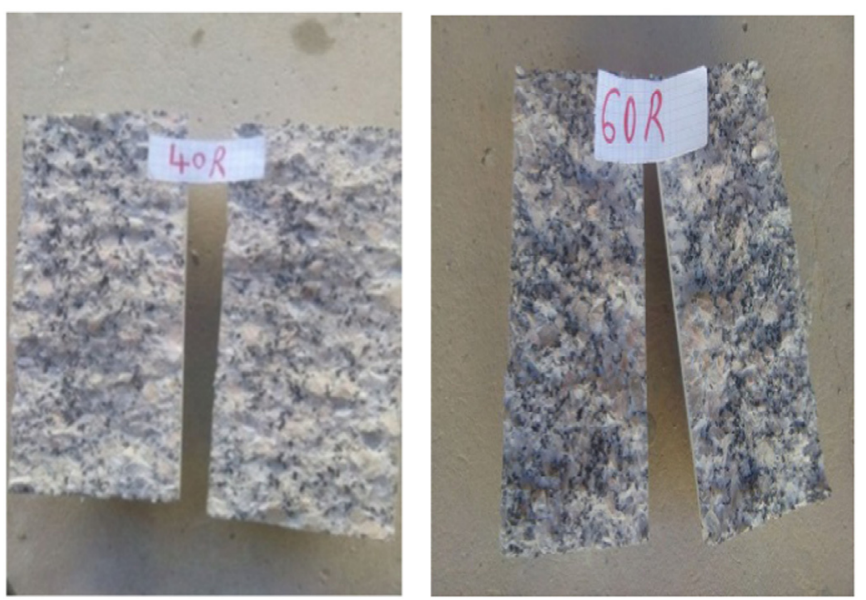

Fig. 14. 40RW and 60RW specimens failure pattern after split tensile test.

solubility of SP in water, which resulted from the small chemical stabilizers amount $(\mathrm{CaO}+\mathrm{MgO}=2.4)$ when compared to the GP one $(\mathrm{CaO}+\mathrm{MgO}=10.82 \%)$. Guettala et al. [46] investigated the partial replacement of cement by sand powder in cement pastes and confirmed that in the first seven days, the compressive strength is low for all samples, whereas the following periods, the compressive strength increases significantly.

A pronounced increase in the 28 days compressive strength of all mixes modified with GP and SP compared to the C-ref and the common rubberized concrete is frequently accompanied by the improvement in other properties such as tensile strength (Fig. 10). It is established that the combined incorporation of (RW-GP) and (RW-SP), respectively, mitigates the negative effect of used RW separately on the concrete strength at the late time. This beneficial effect of glass powder on the compressive strength rubberized concretes was much higher for RW contents of $10 \%$ and $20 \%$ by a gain of $7.3 \%$ and $5.24 \%$, respectively. This can be explained by the good effect of GP large specific area $\left(1,32 \mathrm{~m}^{2} / \mathrm{g}\right)$ on the bond between rubber particles and the surrounding cement paste. This good effect enhances the interfacial transition zone bonding, which, in turn, significantly enhances the compressive strength of the rubberized concretes. Moreover, it seems that there is a synergetic effect of glass powder and cement, which can be explained by the GP pozzolanic behavior, after increasing the reaction through time, with calcium from portlandite $\mathrm{Ca}(\mathrm{OH})_{2}$. Can be explained by the increase of the chemical composition of the binder, especially $\mathrm{SiO}_{2}$ from glass powder which led to decreasing the calcium hydroxide $(\mathrm{CH})$ quantity and producing a more C-S-H gel, which in turn, decreasing the

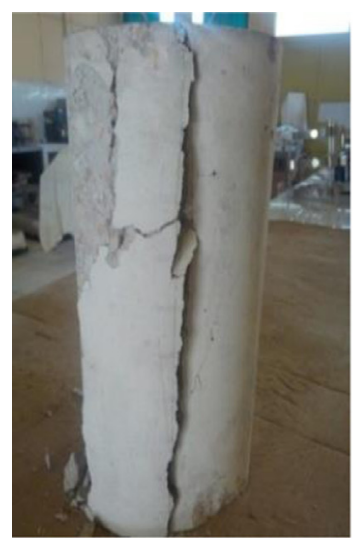

C-ref

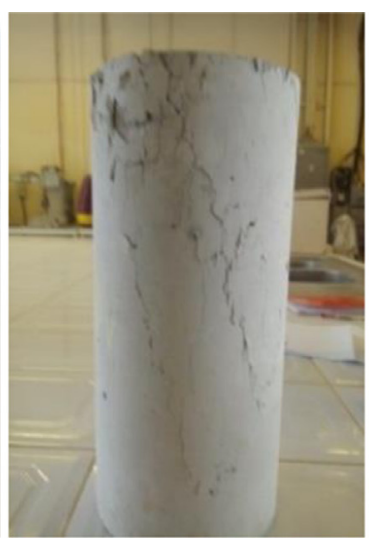

10RW

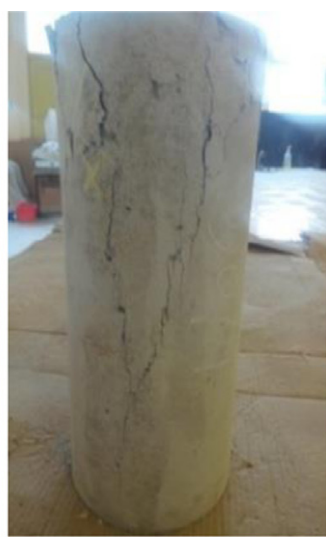

20RW

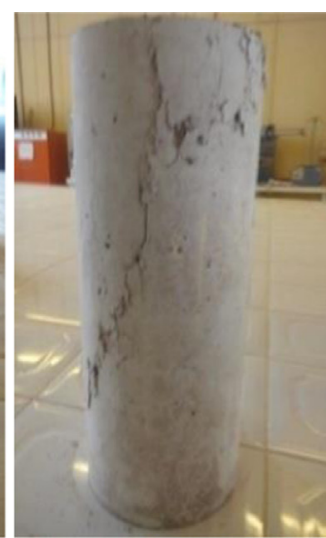

40RW

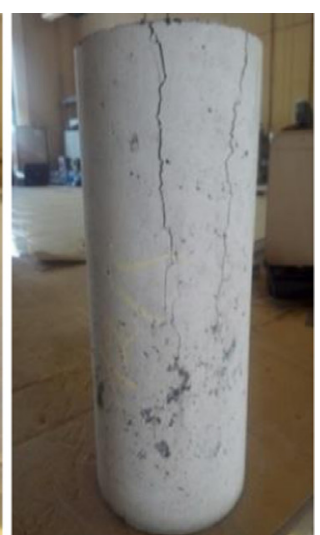

60RW

Fig. 13. Failure pattern of specimens after 28 days compressive strength test. 


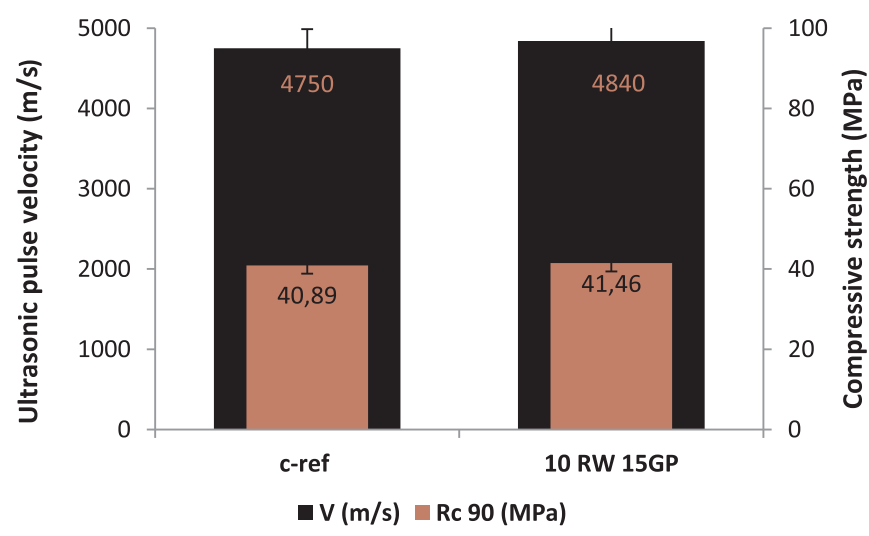

Fig. 15. Effect of glass powder on 90 days compressive strength and ultrasonic pulse velocity of the mixtures C-ref and 10RW15GP.

voids percentage in the mixtures. As reported by Greenberg [48], that the second phase of C-S-H formed, able to improve rubbercrete strength showed by the Eq. (1).

$\mathrm{SiO}_{2}(\mathrm{~s})+\mathrm{Ca}^{2+}(\mathrm{aq})+2 \mathrm{OH}^{-}(\mathrm{aq})=\mathrm{n} 1 \mathrm{CaO} \cdot \mathrm{SiO}_{2} \cdot \mathrm{n} 2 \mathrm{H}_{2} \mathrm{O}(\mathrm{s})$

According to $[31,33,41,48,49]$, the amorphous silica in glass powder appeared more active with lime and forms C-S-H at a later stage of hydration. The mix with $10 \% \mathrm{RW}$ and $15 \%$ GP is the best one compared to the common rubberized concretes, which is associated to a high compressive strength above $36.01 \mathrm{MPa}$ at 28 days. With the same mixture, the 90 days compressive strength was superior to both the reference concrete without, and with RW and achieved $41.46 \mathrm{MPa}$ (Fig. 15). This result has further strengthened our confidence that glass powder becomes more effective for concrete strength with time.

Regarding the 28 days strength of composed (RW-SP) concretes, results clearly show the positive combined effect to minimize the strength loss associated with the use of rubber waste separately. As the dune sand powder is siliceous, can have the same physical and pozzolanic benefits than other additions, despite its crystalline character [50]. In the same way according to Arroudj et al. [51] the small content of portlandite provided by the presence of dune sand powder in the cement paste, translated the partial pozzolanic reaction, which contributes to increasing the strength and the compactness of the paste.

It is evident that GP is more effective than SP concerning concrete strength. For example, (10RW15SP) and (10RW15GP) mixes have $10.16 \%$ and $14.49 \%$ increase in 28 days compressive strength respectively. The difference may be explained by the role of the varied particles size, surface texture, grain distribution and the pozzolanic reaction of the powders.

Concerning tensile strength for the mixtures in the presence of the GP and SP with respect to the rubberized control, a slight improvement was detected. We should mention the following examples of the mixes 10RW15GP, 10RW15SP; they were improved $0.43 \%$ and $0.21 \%$ respectively.

\subsection{Ultrasonic pulse velocity}

The results of the ultrasonic speed waves test for all mixtures are shown in Fig. 16. It can be noted that, as expected, the rubber content in the concrete increases, pulse velocity decreases and thus, concrete strength decreases. The pulse velocity values ranged from $4640 \mathrm{~m} / \mathrm{s}$ (Cref) to $3700 \mathrm{~m} / \mathrm{s}(60 \mathrm{RW})$. Li-Jeng Hunag et al. [52] reported that the ultrasonic pulse velocity of concrete increases as the rubber particle replacement percentage decreases. For the study group, 20\% replacement decreases the pulse velocity at 28 days by $506-2548 \mathrm{~m} / \mathrm{s}$, compared to $3054 \mathrm{~m} / \mathrm{s}$ for the control group. This reduction is probably due to the relatively slowing down of ultrasonic pulses when they pass through cracks, voids and flaws filled with air or water caused by the

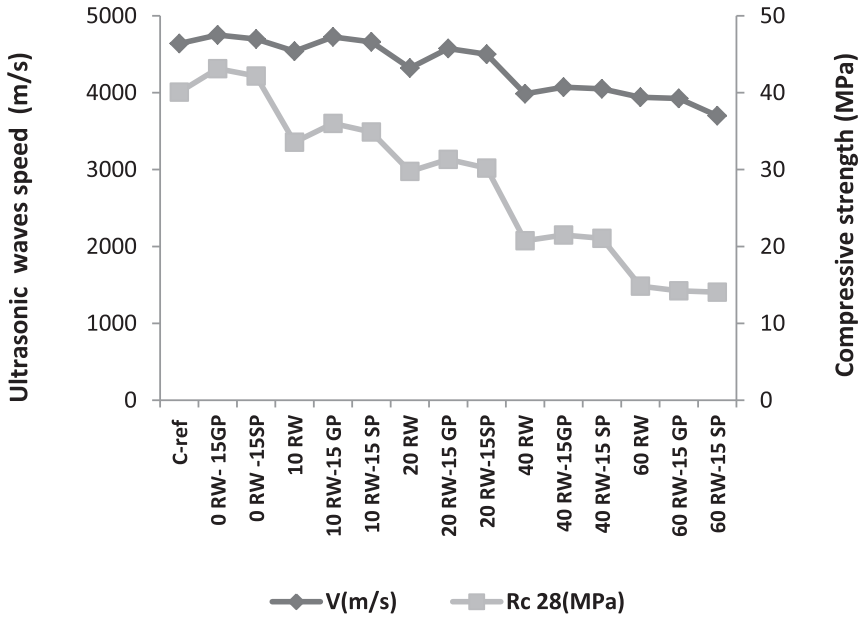

Fig. 16. The ultrasonic pulse velocity and the corresponding compressive strength of the mixtures.

addition of rubber aggregates. Also, the rubber aggregates have higher sound insulation coefficient than mineral aggregates.

To compare the combined effect of RW and (GP and SP) replacement of CS and cement, respectively, with the separate effects; the experimental results relative to the 28 days speed ultrasonic pulse velocity were regrouped in Fig. 16. It has been found that the combined mixtures have a higher 28 days ultrasonic pulse velocity than that of the mixtures containing only RW aggregates, except the 60RW15SP mixture which was negatively affected. It should be noted that the improvement was great with GP than SP. It also can be seen that for C-ref, 0RW15GP and 0RW15SP the pulse velocity were $4640 \mathrm{~m} / \mathrm{s}, 4750 \mathrm{~m} / \mathrm{s}$ and $4698 \mathrm{~m} / \mathrm{s}$, while those of 10RW, 10RW15GP and 10RW15SP mixtures were $4540 \mathrm{~m} / \mathrm{s}, 4725 \mathrm{~m} / \mathrm{s}$ and $4660 \mathrm{~m} / \mathrm{s}$. It may be concluded that the combined incorporation of the (RW-GP) and (RW-SP) compacts and creates a condensed matrix. This can be due to the same reasons mentioned in the Section (3.3) for the compressive strength at 28 days. There is an apparent calibration relationship between the $R_{\mathbf{c} 28}$ of the concrete and its ultrasonic pulse velocity.

\subsection{Deformability and static modulus}

The partial volume incorporation of rubber aggregate, replacing fine aggregate, was found to reduce the modulus of elasticity of concrete, as shown in (Figs. 17 and 18). Each curve represents the average results of three tests conducted at the same age and conditions. For the rubberized concrete, the values of static elastic modulus were 34.49 GPa, 29.03 GPa, 21.69 GPa, 15.19 GPa and 13.10 GPa for C-Ref, 10RW, 20RW, 40RW and 60RW mixtures, respectively. It can be seen

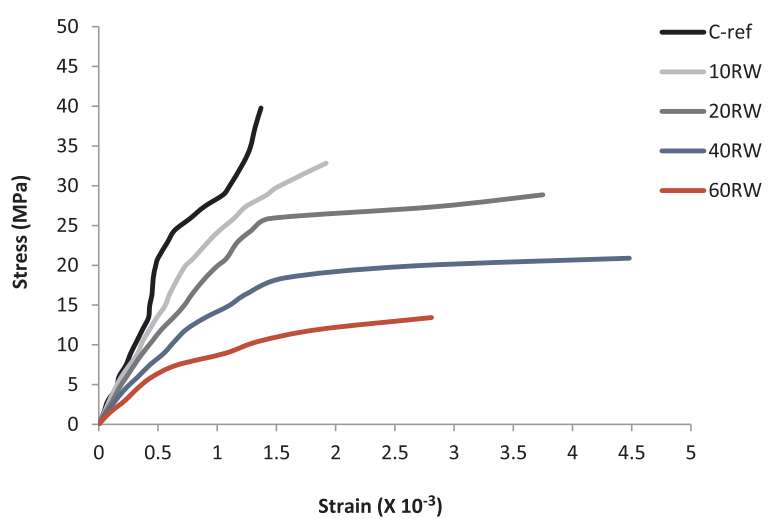

Fig. 17. Stress-Strain curves of rubberized concrete with different rubber contents. 


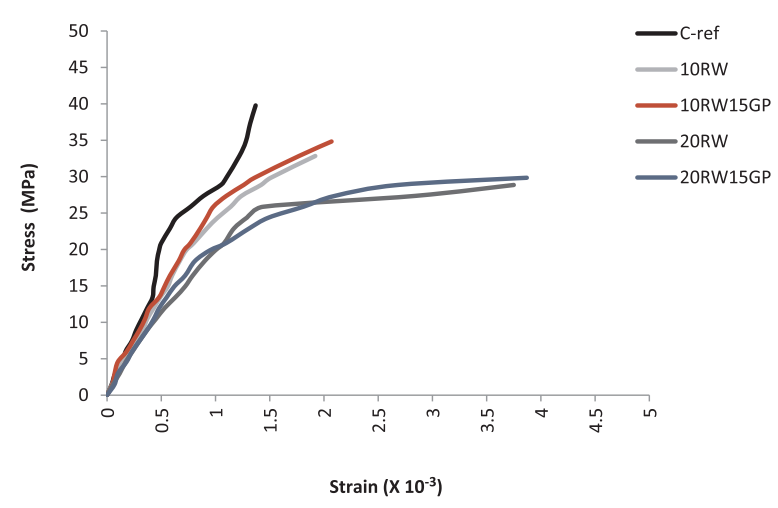

Fig. 18. Stress-Strain curves of rubberized concrete with and without glass powder.

that the increase in rubber aggregate content leads to increasing strain and decreasing static elastic modulus during the reduction in maximum stress. These results similar to that of Aslani et al. [11]. They incorporated three crumb rubber sizes $2 \mathrm{~mm}, 5 \mathrm{~mm}$ and $10 \mathrm{~mm}$ at volume ratios of $10 \%, 20 \%, 30 \%$, and $40 \%$ on the self-compacting concrete. The results indicated that higher strains are generated at lower stress states as the percentage replacement of rubber aggregates is increased. Compared to the brittle reference concrete behavior, the rubberized concrete specimens show ductile behavior. Indeed, the increase in rubber content conducts to the increase in the ductility. In addition, during rubberized concrete failure, a high deformation was detected. When the stress-strain curves are compared, it is easy to note that C-ref is the strongest and the most brittle. However, the mixes 10RW and 20RW have hardening and malleable strain phase until failure, which showed a ductile failure mode compared to the C-ref one. Moreover, 40RW and 60RW have shown great deformability and elastic-plastic behavior mode. Likewise, the mixture with the high rubber content $60 \mathrm{RW}$ is the weakest compared to the reference concrete. It should be noted that for the reference concrete (C-ref) the maximum average peak-stress before failure is $39.78 \mathrm{MPa}$ with the corresponding average strain $\varepsilon=0.137 \%$. For the rubberized samples, these were $32.84 \mathrm{MPa}$, $\varepsilon=0.192 \%, \quad 28.86 \mathrm{MPa}, \quad \varepsilon=0.375 \%, \quad 20.89 \mathrm{MPa}, \varepsilon=0.448 \%$ and $13.93 \mathrm{MPa}, \varepsilon=0.281 \%$ for $10 \mathrm{RW}, 20 \mathrm{RW}, 40 \mathrm{RW}$ and $60 \mathrm{RW}$, respectively. In earlier studies, Dong et al. [18] and Noaman et al. [22] were noted that the rubberized concrete exhibited ductile behavior and differed from that of traditional concrete. According to the same authors, the increase in rubber content led to the increase in ductility and strain capacity, defined as the strain at the maximum stress. Comparable results and analysis were reported by several authors [11,16,19-21].

The effect of the combination of the (RW-GP) incorporation on the elastic modulus $\left(E_{c}\right)$ is shown in Fig. 19. It was equal to $29.5 \mathrm{GPa}$ and 24.77 GPa for 10RW15GP and 20RW15GP respectively. It should be mentioned that the average value of peak stress for the mixes 10RW15GP and 20RW15GP were $34.83 \mathrm{MPa}$, and $29.85 \mathrm{MPa}$

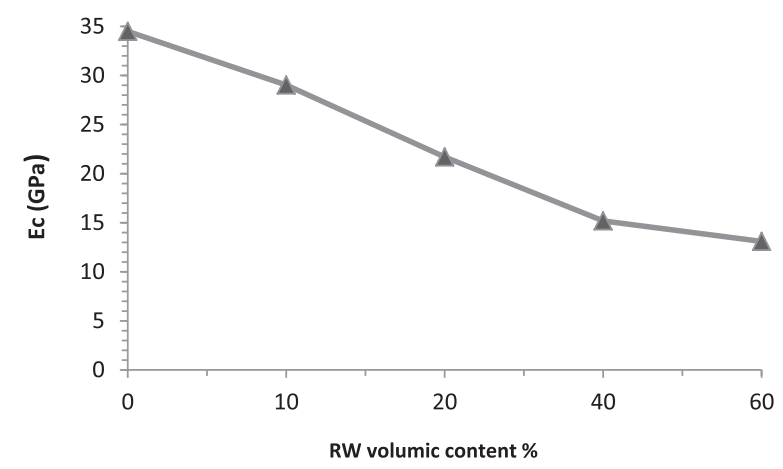

Fig. 19. Effect of the RW content on the static elastic modulus of concrete. corresponding to the average values of a strain of $\varepsilon=0.207 \%$ and $\varepsilon$ $=0.387 \%$, respectively. The slight increase in the elasticity modulus and in the strain corresponding to the peak stress may be due to the positive synergy between the rubber waste and the glass powder. It may be noted that combining the (RW- GP) in concrete slows the elastic and plastic deformations and improves the energy of specimen's deformation before failure compared to those modified with rubber aggregates alone. Glass powder is able to increase the strength and deformation of the rubber mixes, by enhancing their capacity of deformability. Comparable conclusions were achieved by Noaman et al. [22] and Omran et al. [53]. The (RW-GP) concrete becomes to be more ductile and more resistant than rubberized concrete.

\section{Conclusion}

Based on the results of this study about rubberized concrete modified with $15 \%$ in mass of glass and sand powders, the following conclusions can be drawn:

- The combination of the RW and GP offers enhanced workability of concrete due to the low GP and RW water absorptions.

- Higher fresh density was observed for the mixtures prepared by rubber aggregates and glass powder or sand powder. It can be concluded that the composed (RW-GP) particles in concrete create a compromise on fresh density between the separate effect of RW and GP replacement.

- The maximum 28 days compressive strength was obtained by the rubberized concrete modified with glass powder. It was achieved by the 10RW15GP mixture and attained 36,01 MPa.

- The decrease of compressive and tensile strengths verified at 28 days for rubberized concrete with the addition of glass powder. This is may be due to the positive synergy brought by the combination of RW, GP and cement which mitigates the loss of used RW separately in the mixtures. It can be determined that glass powder finely grounded can be used as a good pozzolan in cementitious materials.

- At 90 days the mixture 10RW15GP achieved compressive strength value superior to both, the reference concrete without, and with RW reaching $41.46 \mathrm{MPa}$. This confirms that glass powder became more effectiveness at a later age.

- Glass powder needs a supplementary agent for dissolving the amorphous silica to react with the lime at an early age.

- Glass powder as an artificial material showed a more advantageous behavior than natural sand powder, for $15 \%$ cement replacement by mass.

- The increase in rubber waste leads to decreasing the static elasticity modulus of the concretes. Moreover, the simultaneous incorporation of rubber waste and glass powder increases the ductility of concrete by slowing the elastic and plastic deformations and improving the energy of specimen's deformation before failure.

- This study supports the large-scale recycling of scrap tires as aggregates and glass bottle as filler to be used in the production of concrete. It will surely bring enormous environmental benefits.

- Finally, an investigation about the durability of the prepared mixtures is needed to complete this work; moreover, microscopic justifications of the results remain requested.

\section{Acknowledgements}

The authors would like to grateful for the financial support of Ministère de l'Enseignement Supérieur et de la Recherche Scientifique, République Algérienne Démocratique et Populaire, Programme National Exceptionnel, Algeria and acknowledge the financial support from the Laboratory of Construction Materials, University of Minho, Portugal. 


\section{References}

[1] S. Rafat, R.N. Tarun, Properties of concrete containing scrap-tire rubber-an overview, Waste Manag. 24 (2004) 563-569.

[2] Blessen Skariah Thomas, Ramesh Chandra Gupta, Priyansha Mehra, et al., Performance of high strength rubberized concrete in aggressive environment, Constr. Build. Mater. 83 (2015) 320-326.

[3] H. Trouzine, A. Asroun, A.N.F. Belabdelouahab, et al., Problème des pneus usés en Algérie [problem of waste tires in Algeria], Nat. Technol. 5 (2011) 28-35.

[4] M. Gesoglu, E. Güneyisi, Permeability properties of self-compacting rubberized concretes, Constr. Build. Mater. 25 (2011) 3319-3326.

[5] H. Wang, L.C. YYung, L.H. Hua, A study of the durability properties of waste tire rubber applied to self-compacting concrete, Constr. Build. Mater. 41 (2013) 665-672.

[6] Camille A. Issa, George Salem, Utilization of recycled crumb rubber as fine aggregates in concrete mix design, Constr. Build. Mater. 42 (2013) 48-52.

[7] F. Belabdelouahab, H. Trouzine, Research and enhancement of used tyres such as material innovative in Algeria, Phys. Proc. 55 (2014) 68-74.

[8] Sevket Can Bostanci, Mukesh Limbachiya, Hsein Kew, Portland-composite and composite cement concretes made with coarse recycled and recycled glass sand aggregates: engineering and durability properties, Constr. Build. Mater. 128 (2016) 324-340.

[9] Blessen Skariah Thomas, Ramesh Chandra Gupta, Properties of high strength concrete containing scrap tire rubber, J. Clean. Prod. 11 (2015) 019.

[10] E. Ganjian, M. Khorami, A. Maghsoudi, Scrap-tyre-rubber replacement for ag gregate and filler in concrete, Constr. Build. Mater. 23 (2009) 1828-1836.

[11] Farhad Aslani, Guowei Ma, Dominic Law Yim Wan, et al., Experimental investigation into rubber granules and their effects on the fresh and hardened properties of self-compacting concrete, J. Clean. Prod. 12 (2017) 003.

[12] Jie Li, Mohammad Saberian, Bao Thach Nguyen, Effect of crumb rubber on the mechanical properties of crushed recycled pavement materials, J. Environ. Manag 218 (2018) 291-299.

[13] Mohammad Saberian, Jie Li, Bao Nguyen, et al., Permanent deformation behaviour of pavement base and subbase containing recycle concrete aggregate, coarse and fine crumb rubber, Constr. Build. Mater. 178 (2018) 51-58.

[14] Sandra Bonnet, Matériaux cimentaires à haute déformabilité par incorporation de granulats issus du broyage de pneus usagés [Cementitious materials with high deformability by incorporating aggregates from the grinding of used tires] [dissertation]. Toulouse 3; France. French, 2004.

[15] M.A. Aiello MA, F. Leuzzi, Waste tire rubberized concrete: properties at fresh and hardened state, Waste Manag. 30 (2010) 8-9.

[16] E. Guneyisi, M. Gesoglu, T. Ozturan, Properties of rubberized concretes containing silica fume, J. Cem. Concr. Res. 34 (2004) 2309-2317.

[17] S. Boukour, M.L. Benmalek, Performance evaluation of a resinous cement mortar modified with crushed clay brick and tire rubber aggregate, Constr. Build. Mater. 120 (2016) 473-481.

[18] Qiao Dong, Baoshan Huang, Xiang Shu, Rubber modified concrete improved by chemically active coating and silane coupling agent, Constr. Build. Mater. 48 (2013) 116-123.

[19] Eehab Khalil, Mostafa Abd-Elmohsen, Ahmed M Anwar, Impact resistance of rub berized Self-compacting concrete, Water Sci. 29 (2015) 45-53.

[20] Ali O. Atahan, Ayhan Öner Yücel, Crumb rubber in concrete: static and dynamic evaluation, Constr. Build. Mater. 26 (2013) 617-622.

[21] M. Farhad Aslani, Mechanical properties of waste tire rubber concrete, J. Mater. Civil. Eng. 28 (2016) 04015152. ASCE1.

[22] Ahmed Tareq Noaman, B.H. Abu Bakar, Hazizan Md Akil, Experimental in vestigation on compression toughness of rubberized steel fibre concrete, Constr. Build. Mater. 115 (2016) 163-170.

[23] D. Raghavan, H. Huynh, C. Ferraris, Workability, mechanical properties and chemical stability of a recycled tyre rubber filled cementitious composite, J. Mater. Sci. 33 (1998) 1745-1752.

[24] N. Oikonomou, M. Stefanidou, S. Mavridou, Improvement of the bonding between rubber tire particles and cement paste in cement products, in: Proceedings of 15th Conference on the Technical Chamber of Greece, Alexandroupoli, Greece, 2006, pp. 234-242.

[25] Obinna Onuaguluchi, Daman K. Panesar, Hardened properties of concrete mixtures containing pre-coated crumb rubber and silica fume, J. Clean. Prod. 82 (2014) $125-131$.

[26] Ilker Bekir topçu, Abdullah Demir, Durability of rubberized mortar and concrete, Mater. Civil. Eng. 19 (2007) (2:173).

[27] F. Azevedo, F. Pacheco Torgal, C. Jesus, et al., Properties and durability of HPC with tire rubber wastes, Constr. Build. Mater. 34 (2012) 186-191.

[28] Farhad Aslani, Guowei Ma, Dominic Law Yim Wan, et al., Development of highperformance self-compacting concrete using waste recycled concrete aggregates and rubber granules, J. Clean. Prod. (2018) (02.074).

[29] Farhad Aslani, Ronny Gedeon, Experimental investigation into the properties of self compacting rubberised concrete incorporating polypropylene and steel fibers, Struct. Concr. 182 (2018) (10.1002)

[30] H. Du, K.H. Tan, Concrete with recycled glass as fine aggregates, Acids Mater. J. 111 (2014) 47-58.

[31] M. Pattengil, T.C. Shutt, TC, Use of ground glass as a pozzolan, Albuquergue Symp. on utilisation of Waste Glass in Secondary Products, Albuquerque, New Mexico, U. S.A 137-153.

[32] Recyc-Québec, Le verre fiches informatives [Glass Informational files]. French, 2015.

[33] N.A. Soliman, A. Tagnit-Hamou, Development of ultra-high-performance concrete using glass powder -towards eco-friendly concrete, Constr. Build. Mater. 125 (2016) 600-612.

[34] Ali A. Aliabdo, Abd Elmoaty M. Abd Elmoaty, Ahmed Y. Aboshama, Utilization of waste glass powder in the production of cement and concrete, Constr. Build. Mater. 124 (2016) 866-877.

[35] J.M. Khatib, E.M. Negim, H.S. Sohl, et al., Glass powder utilization in concrete production, Eur. J. Appl. Sci. 4 (4) (2012) 173-176.

[36] D.M. Patil, K.K. Sangle, Experimental investigation of waste glass powder as partial replacement of cement in concrete, Int. J. Adv. Technol. Civ. Eng. 2 (1) (2013) 2231-5721.

[37] M.C. Bignozzi, A. Saccani, L. Barbieri, et al., Glass waste as supplementary cementing materials: the effects of glass chemical composition, Cem. Concr. Compos. 55 (2015) 45-52

[38] N. Schwarz, H. Cam, N. Neithalath, Influence of a fine glass powder on the durability characteristics of concrete and its comparison to fly ash, Cem. Concr. Compos. 30 (2008) 486-496.

[39] M. Mirzahosseini, K.A. Riding, Influence of different particle sizes on reactivity of finely ground glass as supplementary cementitious material (SCM), Cem. Concr Compos. 56 (2015) 95-105.

[40] Maddalena Carsana, Massi miliano Frassoni, Luca Bertolini, Comparison of ground waste glass with other supplementary cementitious materials, Cem. Concr. Compos. 45 (2014) 39-45.

[41] K. Afshinnia, P.R. Rangaraju, Influence of fineness of ground recycled glass on mitigation of alkali-silica reaction in mortar, Constr. Build. Mater. 81 (2015) 257-267.

[42] Hongian Du, Kiang Hwee Tan, Properties of High Volume Glass Powder Concrete, Cem. Concr. Compos. 75 (2017) 22-29.

[43] G. Dreux, J. Festa, Nouveau guide du béton et de ses constituants [New guide of concrete and its constituents], 8th edition, 3rd print. Ed. Eyrolles ISBN13: 978-2212-10231-4. French, 2007.

[44] W. Schmidt, Design Concepts for the Robustness Improvement of Self-Compacting Concrete (Doctoral thesis), Eindhoven University of Technology, Eindhoven Netherlands, 2014.

[45] G.M.S. Islam, M.M. Islam, A. Akter, et al, Green construction materials-Bangladesh perspective, in: Proceedings of the International Conference on Mechanical Engineering and Renewable Energy. (ICMERE2011). Bangladesh, 2011.

[46] Salim Guettala, Bouzidi Mezghiche, Compressive strength and hydration with age of cement pastes containing dune sand powder, Constr. Build. Mater. 25 (2011) 1263-1269.

[47] Valeria Corinaldesi, Alessandro Nardinocchi, Jacopo Donnini, Reuse of recycled glass in mortar manufacturing, European, J. Environ. Civil. Eng. 10 (1080) (2016) 140-151.

[48] S.A. Greenberg, Reaction between silica and calcium hydroxide solutions- I. kinetics, in the temperature range 30 to 85, J. Phys. Chem. 65 (12) (1961) 12-16.

[49] A. Khmiri M, Chemical behaviour of ground waste glass when used as partial cement replacement in mortars, Constr. Build. Mater. 44 (2013) 74-80.

[50] P..Pascal, New Treaty of Inorganic Chemistry (Silicium), Tome VIII, 2nd Issue Paris, France pp. 2-90;23-445, 1965.

[51] K. Arroudj, M.N. Oudjit, Influence of the sand of dune finely crushed on the hydration of cements, 2éme Colloque Maghrébin en Génie Civil Biskra Algérie. Biskra, Algérie 10 et 11 Décembre, 2002.

[52] Li-Jeng Hunag, Her-Yung Wan, Yu-Wu Wu, Properties of the mechanical in controlled low-strength rubber lightweight aggregate concrete (CLSRLC), Constr. Build. Mater. 112 (2016) 1054-1058.

[53] Ahmed Omran, Arezki Tagnit-Hamou, Performance of glass-powder concrete in field applications, Constr. Build. Mater. 109 (2016) 84-95. 